\title{
ORIGINAL ARTICLE \\ Disturbed cingulate glutamate metabolism in adults with high-functioning autism spectrum disorder: evidence in support of the excitatory/inhibitory imbalance hypothesis
}

\author{
L Tebartz van Elst ${ }^{1,2,6}$, S Maier ${ }^{1,6}$, T Fangmeier ${ }^{1,2}$, D Endres ${ }^{1}$, GT Mueller ${ }^{1}$, K Nickel ${ }^{1}$, D Ebert ${ }^{1,2}$, T Lange $^{3,4}, \mathrm{~J} \mathrm{Hennig}^{3}, \mathrm{M} \mathrm{Biscaldi}^{1,2,5}$, \\ A Riedel ${ }^{2,7}$ and E Perlov ${ }^{1,7}$
}

\begin{abstract}
Over the last few years, awareness of autism spectrum disorder (ASD) in adults has increased. The precise etiology of ASD is still unresolved. Animal research, genetic and postmortem studies suggest that the glutamate (Glu) system has an important role, possibly related to a cybernetic imbalance between neuronal excitation and inhibition. To clarify the possible disruption of Glu metabolism in adults with high-functioning autism, we performed a magnetic resonance spectroscopy (MRS) study investigating the anterior cingulate cortex (ACC) and the cerebellum in adults with high-functioning ASD. Twenty-nine adult patients with high-functioning ASD and 29 carefully matched healthy volunteers underwent MRS scanning of the pregenual ACC and the left cerebellar hemisphere. Metabolic data were compared between groups and were correlated with psychometric measures of autistic features. We found a significant decrease in the cingulate $\mathrm{N}$-acetyl-aspartate (NAA) and the combined Glu and glutamine (Glx) signals in adults with ASD, whereas we did not find other metabolic abnormalities in the ACC or the cerebellum. The Glx signal correlated significantly with psychometric measures of autism, particularly with communication deficits. Our data support the hypothesis that there is a link between disturbances of the cingulate NAA and Glx metabolism, and autism. The findings are discussed in the context of the hypothesis of excitatory/inhibitory imbalance in autism. Further research should clarify the specificity and dynamics of these findings regarding other neuropsychiatric disorders and other brain areas.
\end{abstract}

Molecular Psychiatry (2014) 19, 1314-1325; doi:10.1038/mp.2014.62; published online 22 July 2014

\section{INTRODUCTION}

Deficits in social cognition and in communication skills, a high need for routines, and highly circumscribed interests form the core features of autism spectrum disorders (ASDs). ICD-10 and DSM-IV distinguish early infantile autism (ICD-10 F84.0, respective autistic disorder DSM-IV 299.00) from Asperger syndrome (AS; ICD-10 F84.5, DSM-IV 299.80). Recently, however, there has been a clear trend in the scientific community to unify these concepts into a single category called ASD in DSM-5 (http://www.dsm5.org).

Prevalence figures for ASD vary between 1 and $2.7 \%^{1-3}$ depending on the population investigated. The most recent figures from the Centers for Disease Control and Prevention estimate a prevalence of 11.3 in 1000 (1.13\%) affected children (range 4.8-21.2 per 10000). ${ }^{1}$ Given this prevalence rate and the fact that ASD is a lifelong condition, it is of importance for adult psychiatry and psychotherapy. In addition, particularly high-functioning autism is associated with significant psychiatric comorbidities such as depression (53\%), anxiety (50\%), attention deficit hyperactivity disorder (ADHD) (43\%), obsessive-compulsive disorder (24\%), tic disorder (20\%) and psychotic disorder $(12 \%){ }^{4}$ which illustrates that ASD might be a basic neurodevelopmental neuropsychiatric disorder, secondary to which many other more classical psychiatric conditions arise. ${ }^{5}$

\section{High-functioning idiopathic autism as a possibly more homogenous subgroup}

Traditionally, autism has been conceptualized as a severe form of neurodevelopmental disorder associated with mental retardation and severe deficits of intelligence and language in the majority of cases. ${ }^{6}$ However, recent research has indicated that there is a broad variety of different severities and phenotypes of ASD including those with normal or even above-average intelligence. ${ }^{7}$ Secondary and syndromal forms of ASD, which often coexist with subnormal intelligence quotient (IQ) and learning disabilities, are increasingly distinguished from primary familial but probably not mono- or oligogenetic forms. ${ }^{6-8}$ Theoretical considerations as well as clinical observations support the assumption that the latter subgroup, that is, familial but nonsyndromal and nonsecondary variants of ASD, might more often be associated with normal or even above-average intelligence scores. ${ }^{5,7}$

On the basis of difficulties in distinguishing the main current autistic categories, AS and early infantile autism, clinically, ${ }^{9,10}$ these categories have been unified and called ASD in the DSM-5

\footnotetext{
${ }^{1}$ Section for Experimental Neuropsychiatry, Department for Psychiatry and Psychotherapy, Albert-Ludwigs-University, Freiburg, Germany; ${ }^{2}$ Universitäres Zentrum Autismus Spektrum, Albert-Ludwigs-University, Freiburg, Germany; ${ }^{3}$ Department for Radiology, Medical Physics, University Medical Center Freiburg, Freiburg, Germany; ${ }^{4}$ Freiburg Institute for Advanced Studies (FRIAS), Albert-Ludwigs-University, Freiburg, Germany and ${ }^{5}$ Department for Child \& Adolescent Psychiatry \& Psychotherapy, Albert-Ludwigs-University, Freiburg, Germany. Correspondence: Professor L Tebartz van Elst, Clinic for Psychiatry and Psychotherapy, Section for Experimental Neuropsychiatry, Albert-Ludwigs-University, Hauptstrasse 5, Freiburg 79104, Germany.

${ }^{6}$ These authors contributed equally to this paper.

${ }^{7}$ These senior authors contributed equally to this paper.

Received 5 December 2013; revised 28 March 2014; accepted 12 May 2014; published online 22 July 2014
} 
(http://www.dsm5.org). This ASD category does not distinguish between high-functioning and low-functioning variants or between autistic disorder and AS. This might make sense from a clinical perspective. ${ }^{9}$ From a research perspective, however, studying the category of ASD without distinguishing high-functioning from low-functioning variants or secondary and syndromal variants of ASD from primary idiopathic familial variants probably results in particularly heterogeneous study samples. ${ }^{5}$ In research, this approach could blur respective findings. Therefore, in this study, we concentrated on patients with nonsecondary and nonsyndromal forms of ASD, who fulfill the diagnostic criteria for AS according to DSM-IV 299.80 and ICD-10 F84.5, with aboveaverage IQ, in an attempt to create a possibly homogenous study sample from an etiological and pathogenetic point of view.

\section{Etiology of ASD}

The precise etiology of ASD is unknown and probably heterogeneous. ${ }^{6}$ Autism can be caused by single genes or in the context of syndromes, which in turn are probably caused by single nonrecognized gene defects or a small number of gene defects. ${ }^{6,11}$ In addition, ASD may arise secondary to other acquired central nervous system diseases such as encephalitis. For this paper, all these variants are considered secondary or syndromal variants of autism. ${ }^{5}$ However, in the majority of cases, there are no such recognized syndromes or putative causes of autism. Still, the family history is often positive, and there is obviously a strong etiological factor of inheritance. ${ }^{11}$ This group is considered the idiopathic or primary variant of ASD for this paper. ${ }^{5}$

The following considerations focus on this group of patients with primary ASD. There is general agreement that multiple genes alone or more likely in combination contribute to the pathogenesis of autism in these primary idiopathic patients. ${ }^{11}$ These genes or subgroups of these genes might also increase the risk for other neuropsychiatric disorders frequently linked to autism, such as epilepsy $^{12,13}$ or schizophrenia. ${ }^{14,15}$

Several authors have put forward the idea that such genetic alterations lead to an imbalance of excitation and inhibition in cortical regions, which might be a critical pathogenetic correlate of autistic symptoms. ${ }^{16-18}$ Such an imbalance could also explain the well-recognized link between epilepsy (as the classical form of a hyperexcitatory central nervous system disorder) and autism. ${ }^{19-23}$

Pathophysiological changes in the glutamate (Glu) and $\gamma$-aminobutyric acid (GABA) metabolism might be critical for such an excitatory-inhibitory imbalance. Glu is the most important excitatory and GABA the most important inhibitory neurotransmitter in the brain. In fact, many genetic studies found abnormal signals in genes with direct links to Glu neurotransmission. ${ }^{24-34}$ In addition, in animal models of autism, prenatal valproic acid exposure results in an autistic behavioral animal phenotype together with altered cerebral Glu metabolism. ${ }^{35,36}$

Postmortem studies also found evidence of Glu dysfunction in brain tissue of autistic patients. ${ }^{37}$ Recently, Shimmura et al. ${ }^{38}$ reported increased plasma levels of Glu and decreased levels of glutamine $(\mathrm{Gln})$ in 23 children with high-functioning autism compared with 22 control subjects. The signal had a strong effect size of 1.13 and 1.36 , respectively, and correctly classified patients in $91 \%$ of cases. In the latest postmortem study by the same group, the authors describe decreased glutaminase activity (the enzyme breaking down Glu) in the anterior cingulate cortex (ACC) of seven individuals with autism. ${ }^{39}$

In summary, there is a cumulating body of evidence pointing to the critical role of the Glu system in the pathogenesis of autism. Changes in Glu metabolism might translate into an imbalance of the excitation/inhibition equilibrium of cortical networks that in turn are related to autistic symptoms. From a theoretical point of view, two contradictory Glu hypotheses have been put forward:
Carlson introduced the idea that autism is a hypoglutamatergic disorder based on findings in animal research where hypoglutamatergic animals displayed an autistic behavioral pattern. ${ }^{40}$ In contrast, Fatemi proposed a hyperglutamatergic hypothesis of autism. ${ }^{41}$ This assumption was based on the observation that the enzyme that converts Glu to GABA showed decreased activity in autism, therefore resulting in hyperglutamatergic cerebral states. ${ }^{42}$ These ideas seem to be contradictory at first glance. However, they might be reconciled within the theory of a disturbed excitation/inhibition equilibrium in autism, because the hypo- and the hyperglutamatergic states result in a disturbance of this equilibrium.

Magnetic resonance spectroscopy as a tool for assessing Glu activity in vivo

Presently, proton magnetic resonance spectroscopy (1H-MRS or briefly MRS), the only method available for noninvasive and nonradioactive in vivo assessment of Glu neurotransmission, is an ideal tool for investigating cerebral metabolism in autism. ${ }^{43}$ Although early MRS studies focused on stronger MRS signals, such as $N$-acetyl-aspartate (NAA) as a putative marker of neuronal integrity, progress in MRS acquisition, and postprocessing technology have enabled researchers to measure Glu and Gln signals with increasing accuracy. ${ }^{44}$

Glu is the most important excitatory neurotransmitter in the human cerebral cortex. Following synaptic release, Glu is converted to Gln by adjacent astroglia. Gln is then recycled to Glu via mitochondrial Glu synthesis. Glu-Gln cycling is closely coupled to glial glucose utilization and lactate production, and GIn is possibly a more sensitive indicator of Glu neurotransmission than Glu itself. The spectral peaks of Gln and Glu overlap considerably and therefore are often denoted collectively as the Glu and Gln (GIx) peak. ${ }^{45}$ Figure 1 illustrates the Glx signals in a typical MRS spectrum from the ACC and the cerebellum as assessed in this study (see Figure 1).

\section{Previous MRS findings in ASD}

Thus far, to our knowledge, only 22 MRS studies have been performed in ASD. ${ }^{46-67}$ Table 1 summarizes these studies regarding methods, study samples, regions, and findings.

Many of these studies examined small samples, and quite a few have serious methodological problems. Most studies tested mixed groups regarding age (children and adolescents) or IQ, or just patients with subnormal IQ, and did not analyze Glu signals as this was too difficult to detect in early MRS research. Most studies that analyzed the Glu signal also found respective abnormalities. However, not surprisingly, the direction of these abnormalities varied depending on the age group, the region investigated and the sample characteristics. Three recent meta-analyses of all available MRS data concluded that metabolic abnormalities as measured with MRS tend to decrease and normalize with age and therefore are age dependent. ${ }^{43,68,69}$

\section{Rationale of our study}

Taking all presented evidence, the aim of this study was to investigate the Glu signal in autism using MRS. As there is evidence of continuous metabolic change during development, this study focused only on adult patients. Given the possible link between syndromal and secondary forms of autism and low IQ, we decided to study only patients with above-average IQ (that is, $I Q>100)$. As specific changes in Glu metabolism have recently been reported in the ACC in postmortem research, ${ }^{39}$ we focused on this region of interest and chose the cerebellum as another noncortical comparator region of interest, which has frequently been implicated in the pathophysiology of autism. ${ }^{6}$ We chose to study the left cerebellar hemisphere to enable comparability with 

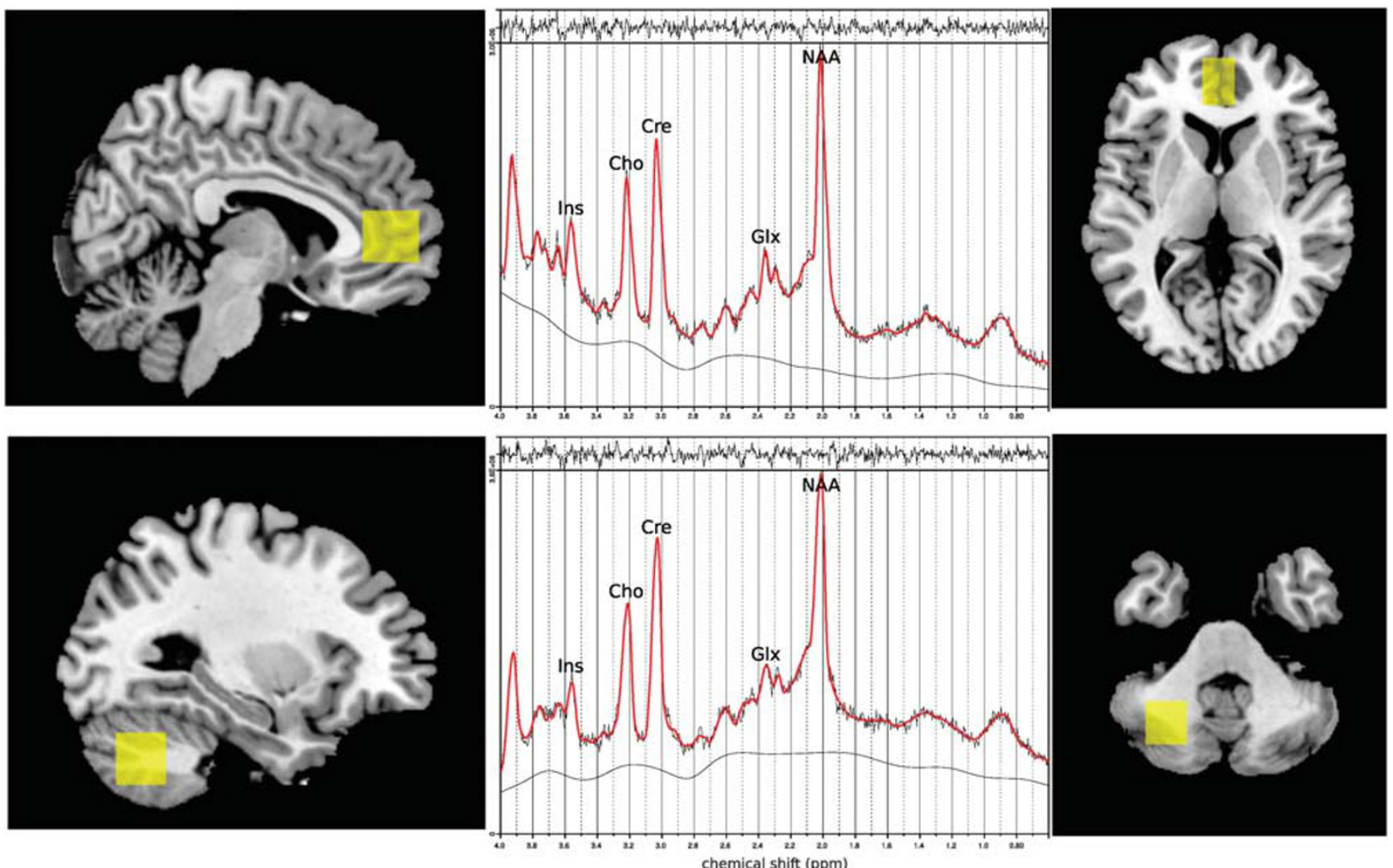

Figure 1. Illustration of the voxel position of the pregenual anterior cingulate (upper row) and the cerebellar MRS voxel of interest (lower row) with respective spectra. Glx, glutamate and glutamine.

other spectroscopic findings in a large government-funded study of more than 100 adults with ADHD by our group. ${ }^{70}$ As previous studies had reported increased ${ }^{55}$ as well as decreased Glu signals in this region, ${ }^{47}$ the working hypothesis was not directed, but we expected Glu signal changes in patients with ASD.

\section{MATERIALS AND METHODS}

\section{Participants}

After approval was received from the local ethics committee, all patients were recruited at the Freiburg Center for the Diagnosis and Treatment of Autism (University center for autism spectrum, Universitäres Zentrum Autismus Spektrum Freiburg, UZAS; http://www.uniklinik-freiburg.de/ psych/live/patientenversorgung/schwerpunkte/schwerpunkt-asperger.html). The study included only patients who fulfilled the diagnostic criteria for AS according to ICD-10 F84.5 and DSM-IV 299.80. The diagnostic process was organized according to the recommendations of the NICE guidelines for adult autism (National Institute for Health and Clinical Excellence: Autism in Adults: full guideline http://guidance.nice.org.uk/CG142/NICEGuidance/ pdf/English). Briefly, the clinical diagnosis of ASD and AS was established as a consensus diagnosis of a multiprofessional team following a structured diagnostic procedure. The clinical diagnosis includes a thorough generally multisession history taking of the patient focusing on the development of autistic symptoms throughout the biography. In addition, a history of the caregivers (parents, partners, siblings and so on) and behavioral observations were essential components of this process, which usually took several sessions of 2 or more hours. Psychometric tools included the following instruments in routine use before clinical assessment: $\mathrm{AQ}_{1}^{71} \mathrm{EQ}^{72} \mathrm{ASAS}^{73} \mathrm{SRS}_{1}^{74} \mathrm{BVAQ}_{1}^{75} \mathrm{AAA}_{1}^{76} \mathrm{WURS}^{77}$ and $\mathrm{BDI}^{78}$ In addition, instruments such as the $A D I-R^{79}$ and $\mathrm{ADOS}^{80}$ or behavioral assessments as an in-patient were used in selected and unclear cases. The multiprofessional diagnostic team consisted of three experienced senior consultant psychiatrists (DE, AR and LTVE) and two senior fully qualified psychologists ( $\mathrm{AF}$ and $\mathrm{AL}$ ). The final consensus diagnosis was made by all persons involved in the diagnostic process, which invariably included at least two experienced consultant psychiatrists or psychologists. In the present study, the control participants were also assessed clinically and completed the $\mathrm{AQ}$ and $\mathrm{EQ}$ questionnaire. To assess general crystalline intelligence, all participants completed the Multiple-Choice Word Test B. ${ }^{81}$ Patients with other relevant medical or neurological diseases, particularly epilepsy and seizures, and patients with a history of schizophrenia, bipolar disorder or any other psychiatric axis I disorder apart from depression and anxiety were excluded from the study.

\section{Matching procedures}

Control subjects were studied and recruited for an ongoing longitudinal ADHD multicenter study funded by the German Ministry of Education and Research (BMBF 01GV0606). When the matched controls were chosen for the 29 patients with ASD, the pool of control participants consisted of 90 healthy and extensively investigated subjects. On the basis of this sample, an optimal matching procedure was performed by applying a multidimensional matching approach using in-house software to optimally account for between-group differences in age, sex and premorbid verbal intelligence (see CP Kaller, forthcoming/unpublished toolbox). This resulted in an individually matched control group for the 29 patients included.

\section{Imaging procedures}

MRI scans were acquired following written informed consent.

\section{Image acquisition}

A standard magnetization-prepared rapid gradient echo T1-weighted anatomical scan was obtained (relaxation time $=2200 \mathrm{~ms}$, echo time $=4.11$ $\mathrm{ms}$, flip angle $=12^{\circ}$, field of view $=256 \times 256 \mathrm{~mm}^{2}$, voxel size $=1 \times 1 \times 1$ $\mathrm{mm}^{3}$ ) on a Siemens Magnetom TIM Trio system (Erlangen, Germany) equipped with a 12-channel head coil. 
Table 1. Summary of previous MRS findings in ASD

\begin{tabular}{|c|c|c|c|c|c|}
\hline Study & Sample & $\begin{array}{l}\text { n Patients per } \\
\text { control subjects }\end{array}$ & Method & Region(s) & Findings \\
\hline Murphy et $a l^{54}$ & Adults, Asperger syndrome & 14 per 18 & $1.5 \mathrm{~T} 1 \mathrm{H}-\mathrm{MRS}$ (PRESS) & Right prefrontal and parietal lobes & NAA, Cre, Cho higher in prefrontal lobe \\
\hline Fayed and Modrego ${ }^{53}$ & Children & 21 per 12 & 1.5 T $1 \mathrm{H}-\mathrm{MRS}$ (PRESS) & Left centrum semiovale (white matter) & No significant differences \\
\hline Page et al. $^{55}$ & Adults, normal IQ & 25 per 21 & 1.5 T 1H-MRS (PRESS) & $\begin{array}{l}\text { Right parietal cortex, } \\
\text { hippocampus-amygdala }\end{array}$ & $\begin{array}{l}\text { Cre and Glx higher in right hippocampus- } \\
\text { amygdala region }\end{array}$ \\
\hline Friedman et al. ${ }^{56}$ & Children, 3-4 years & 45 per 22 & $1.5 \mathrm{~T} \mathrm{CSI}$ & TLs, BGs (white and gray matter) & NAA, Cho, Cre and Ins lower in gray matter \\
\hline Endo et al. ${ }^{52}$ & Children, mean 12.9 years & 38 per 16 & 1.5 T 1H-MRS (PRESS) & Medial TL, MPFC, cerebellar vermis & NAA/Cre lower in MTL \\
\hline Oner et al. ${ }^{57}$ & Adults, Asperger syndrome & 14 per 21 & $1.5 \mathrm{~T} \mathrm{CSI}$ & Right DLPFC and ACC & NAA/Cho higher in ACC \\
\hline Zeegers et al. ${ }^{60}$ & $\begin{array}{l}\text { Boys with and without mental } \\
\text { retardation }\end{array}$ & 25 per 12 & Unclear & Unclear & No differences between groups \\
\hline Hardan et $a l^{51}$ & Boys $8-15$ years, IQ $>70$ & 18 per 16 & 1.5 T CSI (STEAM) & Thalamus right, left & Left thalamus: lower NAA, Cre, Cho \\
\hline Montag et al. ${ }^{50}$ & Healthy controls, adults & 0 per 17 & $3 \mathrm{~T}$ 1H-MRS (PRESS) & ACC DLPFC & $\begin{array}{l}\text { Negative correlation of perspective taking } \\
\text { with GIx level in DLPFC }\end{array}$ \\
\hline Vasconcelos et al. ${ }^{59}$ & $\begin{array}{l}\text { Children and controls, median } \\
\text { age } 9.3 \text { years }\end{array}$ & 10 per 10 & 1.5 T PRESS & $\begin{array}{l}\text { Bilateral ACC, left striatum, left cerebellar } \\
\text { hemisphere and left frontal lobe }\end{array}$ & $\begin{array}{l}\text { Increase in } \mathrm{ml} \text { and Cho in } A C C \text { and } \mathrm{ml} / \mathrm{Cre} \\
\text { ratio in } \mathrm{ACC} \text { and left striatum }\end{array}$ \\
\hline Suzuki et al. ${ }^{49}$ & Adults, high-functioning & 12 per 12 & $1.5 \mathrm{~T}$ & $\begin{array}{l}\text { Left hippocampal region, right cerebellar } \\
\text { hemisphere }\end{array}$ & $\begin{array}{l}\text { Cho and Cre higher in hippocampal region, } \\
\text { NAA lower in cerebellum }\end{array}$ \\
\hline Fuji et al..$^{48}$ & Children, 2-13 years, low IQ & 31 per 28 & 1.5 T 1H-MRS (PRESS) & ACC DLPFC & $\begin{array}{l}\text { ACC: NAA/Cre low } \\
\text { Left DLPFC: NAA/Cre low, correlates with } \\
\text { social ability }\end{array}$ \\
\hline Bernardi et al. ${ }^{47}$ & High-functioning adults & 14 per 14 & $3 \mathrm{~T} 1 \mathrm{H}-\mathrm{MRS}$ & ACC, thalamus, TPJ, intraparietal sulcus & Lower Glx in right ACC, lower Ins in left TPJ. \\
\hline Harada et al..$^{58}$ & Children $2-11$ years & 12 per 10 & $\begin{array}{l}3 \text { T } 1 \text { H-MRS (MEGA- } \\
\text { PRESS) }\end{array}$ & Frontal lobe, lenticular nucleus & GABA and GABA/NAA lower in frontal lobe \\
\hline Corrigan et al. ${ }^{46}$ & $\begin{array}{l}\text { Children in subgroups } 3-4,6-7 \\
\text { and } 9-10 \text { years }\end{array}$ & 109 per 110 & 1.5 T PEPSI & Planar MRS imaging analysis of lactate & No differences in lactate level \\
\hline Kubas et al. ${ }^{61}$ & $\begin{array}{l}\text { Autistic children } 12-15 \text { years, } \\
\text { matched controls }\end{array}$ & 12 per 16 & Details not available & Bilateral frontal lobe; details not available & $\begin{array}{l}\text { Differences in NAA/Cre, GABA/Cre, Glx/Cre } \\
\text { and } \mathrm{ml} / \mathrm{Cre}\end{array}$ \\
\hline Bejjani et al. ${ }^{62}$ & $\begin{array}{l}\text { Study 1: children with ASD and } \\
\text { controls matched for age only } \\
\text { Study 2: children and } \\
\text { matched controls }\end{array}$ & $\begin{array}{c}8 \text { per } 10, \\
\text { IQ range } 74-137 \\
26 / 16, \\
\text { IQ range } 65-142\end{array}$ & 1.5 T PRESS & $\begin{array}{l}\text { Midline pACC, single-voxel MRS } \\
\text { MRS imaging of bilateral pACC }\end{array}$ & $\begin{array}{l}\text { Elevation of Glx signal, decrement of Cre } \\
\text { Elevation of Glx, Cre, NAA in right pACC }\end{array}$ \\
\hline Joshi et al. ${ }^{63}$ & $\begin{array}{l}\text { Adolescent males (age range: } \\
\text { 12-17 years); mean IQ: } 108 \text { (range: } \\
85-127 \text { ) and controls }\end{array}$ & 7 per 7 & $4 \mathrm{~T}$ & ACC and right medial temporal lobe & $\begin{array}{l}\text { Increased glutamate in ACC and trend to } \\
\text { decreased glutamate in temporal lobe }\end{array}$ \\
\hline Aoki et al. ${ }^{64}$ & $\begin{array}{l}\text { Adults with high-functioning } \\
\text { ASD and controls }\end{array}$ & 24 per 25 & 3 T PRESS & Medial prefrontal cortex & $\begin{array}{l}\text { Increased NAA in ASD; NAA loss with age } \\
\text { only in controls not in ASD }\end{array}$ \\
\hline Mori et al. ${ }^{65}$ & $\begin{array}{l}\text { Autistic children ( } 3-6 \text { years), } \\
\text { age-matched controls, boys and girls }\end{array}$ & 77 per 55 & 1.5 T STEAM & $\begin{array}{l}\text { Left amygdala and the bilateral } \\
\text { orbitofrontal cortex }\end{array}$ & $\begin{array}{l}\text { NAA reduction in left amygdala and bilateral } \\
\text { OFC, NAA correlated with social quotient. }\end{array}$ \\
\hline Brown et al. ${ }^{66}$ & $\begin{array}{l}\text { Adult patients, parents of } \\
\text { patients, healthy controls }\end{array}$ & $13 / 15$ per 15 & 3 T PRESS & $\begin{array}{l}\text { Left and right hemisphere auditory } \\
\text { cortical voxels }\end{array}$ & $\begin{array}{l}\text { Higher Glx, NAA and Cre concentrations in } \\
\text { ASD than in control subjects. }\end{array}$ \\
\hline Rojas et al. ${ }^{67}$ & Autistic children, siblings, controls & $\begin{array}{l}17 / 14 \text { siblings } \\
\text { per } 17 \text { controls }\end{array}$ & 3 T PRESS & $\begin{array}{l}\text { Auditory cortex in the perisylvian } \\
\text { region of the left hemisphere }\end{array}$ & $\begin{array}{l}\text { Patient GABA/Cre } \\
\text { ratios }<\text { siblings }<\text { controls }\end{array}$ \\
\hline
\end{tabular}

prefrontal cortex; GABA, $\gamma$-aminobutyric acid; Glx, glutamate and glutamine; Ins, myoinositol; IO, intelligence quotient; MPFC, medial prefrontal cortex; MTL, medial temporal lobe; NAA, N-acetyl-aspartate; OFC,

orbitofrontal cortex; PACC, pregenual ACC; PEPSI, proton echo planar spectroscopic imaging; PRESS, point-resolved spectroscopy; SI, spectroscopic imaging; STEAM, stimulated echo aquisition mode; T, tesla; TL, temporal lobe; TPJ, temporoparietal junction; 1H-MRS, proton magnetic resonance spectroscopy. 
Table 2. Summary of demographic and psychometric data of participants

\begin{tabular}{lccc}
\hline & $A S D(\mathrm{n}=29)$ mean (s.d.) & Control $(\mathrm{n}=29)$ mean (s.d.) & Statistics \\
\hline Age & $35.31(9.1)$ & $35.79(8.5)$ & $T=-0.209 ; \mathrm{df}=56, P=0.836$ \\
Gender & $19: 10$ & $19: 10$ & $X^{2}=0.000, \mathrm{df}=1, P=1$ \\
IQ & $125.1(12.0)$ & $124.97(13.4)$ & $T=0.41 ; \mathrm{df}=56, P=0.967$ \\
AQ & $37.66(6.096)$ & $13.17(6.398)$ & $T=14.92 ; \mathrm{df}=56, P<0.000$ \\
EQ & $16.83(8.984)$ & $44.38(9.734)$ & $T=-11.2 ; \mathrm{df}=56, P<0.000$ \\
BDI & $14.69(12.1)$ & $1.72(2.5)$ & $T=5.63 ; \mathrm{df}=56, P<0.000$ \\
WURS & $31.59(13.14)$ & $9.69(8.45)$ & $T=7.55 ; \mathrm{df}=56, P<0.000$ \\
\hline
\end{tabular}

Abbreviations: $A Q$, autism quotient; $A S D$, autism spectrum disorder; $B D I$, Beck Depression Inventory score; $E Q$, empathy quotient; $I Q$, intelligence quotient; WURS, Wender-Utah Rating scale. For reference see text.

Spectroscopic data were acquired in the pregenual ACC and the left cerebellar hemisphere (see Figure 1 for voxel localization) with a standard PRESS (point-resolved spectroscopy) sequence (echo time $=30 \mathrm{~ms}$, relaxation time $=3000 \mathrm{~ms})$. The $2.5 \times 1.6 \times 2 \mathrm{~cm}^{3}$ ACC volume of interest was located in front of the genu corpus callosum orthogonally to the anterior commissure-posterior commissure line (see Figure 1) according to the disposition of the T1-weighted images for voxel location. The geometry of the volume of interest was defined to cover the maximum amount of gray matter of Brodmann areas 12 and 32 bilaterally in the pregenual ACC region. The $2 \times 2 \times 2 \mathrm{~cm}^{3}$ cerebellar voxel was located in the left hemisphere and comprised parts of lobule VI, lobule Vlla, lobule Vllb, lobule VIIla and lobule VIIIb. The voxel location covered the maximum amount of gray matter and the minimal amount of cerebral fluid to avoid contact with the macromolecules of the brain surfaces, which contaminate MRS spectra. We chose the left hemisphere to enable comparability with other spectroscopic findings in a large cohort of a prospective government-funded ADHD study in adults. ${ }^{70}$

For spectral data analysis and absolute metabolite quantification with the internal water reference method, the well-established and validated LCModel software was used. ${ }^{82}$ Voxel segmentation into the cerebral spinal fluid, gray matter and white matter was performed on the three-dimensional magnetization-prepared rapid gradient echo data set using SPM8 (Statistical Parametric Mapping release 8, London, UK), and metabolite concentrations were corrected accordingly, accounting for different water content in the cerebral spinal fluid, white matter and gray matter.

\section{Statistical analyses}

Metabolite concentrations as assessed in LCModel were transferred to an SPSS database together with all clinical and psychometric data. Metabolites were considered only for further statistical analysis if the Cramér-Rao bounds were below $20 \%{ }^{83}$ First, all dependent variables of interest were tested for normality of distribution using the Kolmogorov-Smirnov test. Then, the data were analyzed with multiple analysis of covariance (MANCOVA). Group was chosen as a factor and the metabolites (NAA, Cre, Cho, Ml, Glu, Glx) as dependent variables. A P-level of 0.05 was chosen as the criterion for significance. To estimate the possible effect of the factor gender, we included this item as a cofactor in the same MANCOVA calculation in the second-level analysis. In addition, to assess the possible confounding effect of the factor medication, the following second-level analyses were performed: we compared 14 completely unmedicated patients with the control group of 29 age-, gender- and IQmatched control subjects using a $t$-test procedure and calculated the factorial analysis of variance with medication as the cofactor. All metabolites that were significant in the first-level group comparison were correlated with psychometric measures of autism (AQ and EQ scores) using Pearson correlations. Significant findings in overall group correlations were further analyzed in the patient and control groups alone.

\section{RESULTS}

Demographic and psychometric data

In Table 2, the demographic and psychometric data of all participants are summarized.

We included 29 patients with high-functioning ASD respective AS and 29 individually matched healthy control subjects into this study, 19 men and 10 women in each group. Both groups had clearly above-average IQs with an average full IQ score of 125 in each group. None of the patients had a primary other axis I psychiatric disorder; however, 9 patients suffered from depression, 3 from nonorganic sleeping disorders and 4 from other psychiatric disorders (1 anxiety disorder, 1 personality disorder, 1 obsessive compulsive disorder, 1 atypical eating disorder). On the basis of a carefully performed longitudinal biographical and developmental analysis of these syndromes, they were all judged to be secondary to ASD. That means that they arose as a consequence of chronic psychosocial stress and life events such as interpersonal problems in private relationships and at school, university or work based on clinical judgment (equivalent to the old concept of reactive depression or reactive anxiety). None of the included patients had a history of seizures, epilepsy, psychosis or symptoms reminiscent of psychosis, bipolar disorder or substance abuse. As a consequence of this high psychiatric comorbidity, only 14 of the 29 patients were completely free of any medication. Fifteen patients were taking psychotropic medication, mostly SSRI or SSNRI $(n=12)$, and atypical or low potent neuroleptics $(n=4)$ as sleeping pills. One patient used clonazepam as a sleeping pill until 2 weeks before scanning.

Psychosocial, school and occupational performance

Table 3 illustrates that in line with high IQ, the school performance of our study sample was above average. Twenty-two patients (75.9\%) and 24 controls (82.8\%) had successfully finished the highest school grade (Abitur) in the German school system. Twelve patients (41.4\%) and 7 controls (24.1\%) had acquired a university degree. However, in spite of this education, only 13 patients (44.8\%) held a regular job, and even fewer $(n=9,31.0 \%)$ held a job that adequately matched their formal qualifications. Six patients (20.7\%) had entered early retirement and were living on social support. Six patients (20.7\%) were married or living in a stable relationship, two were in an unstable relationship (6.9\%), whereas 21 had no relationship (72.4\%). Four patients (13.8\%) had children.

\section{Matching results}

After matching, all patient-control pairs were comparable according to gender, IQ and age as can be seen in Table 2 .

\section{MRS results}

Table 4 summarizes the spectroscopic findings. Patients with ASD displayed significantly decreased NAA, Glu and Glx signals (MANCOVA: Wilks' lambda $=0.762, \quad F=2.659, \mathrm{df}=6, \mathrm{dfE}=51$, $P=0.025$; between-subject effects: NAA MANCOVA: $F=4.150$, $P=0.046$, Glu MANCOVA: $F=9.870, P=0.003$ and Glx MANCOVA: $\mathrm{F}=11.772, P=0.001)$ compared with the healthy control group in the pregenual ACC. The scatterplot in Figure 2 shows this main finding. Including the factor gender as a cofactor in the MANCOVA 
Table 3. Psychosocial characteristics of the patient and control sample

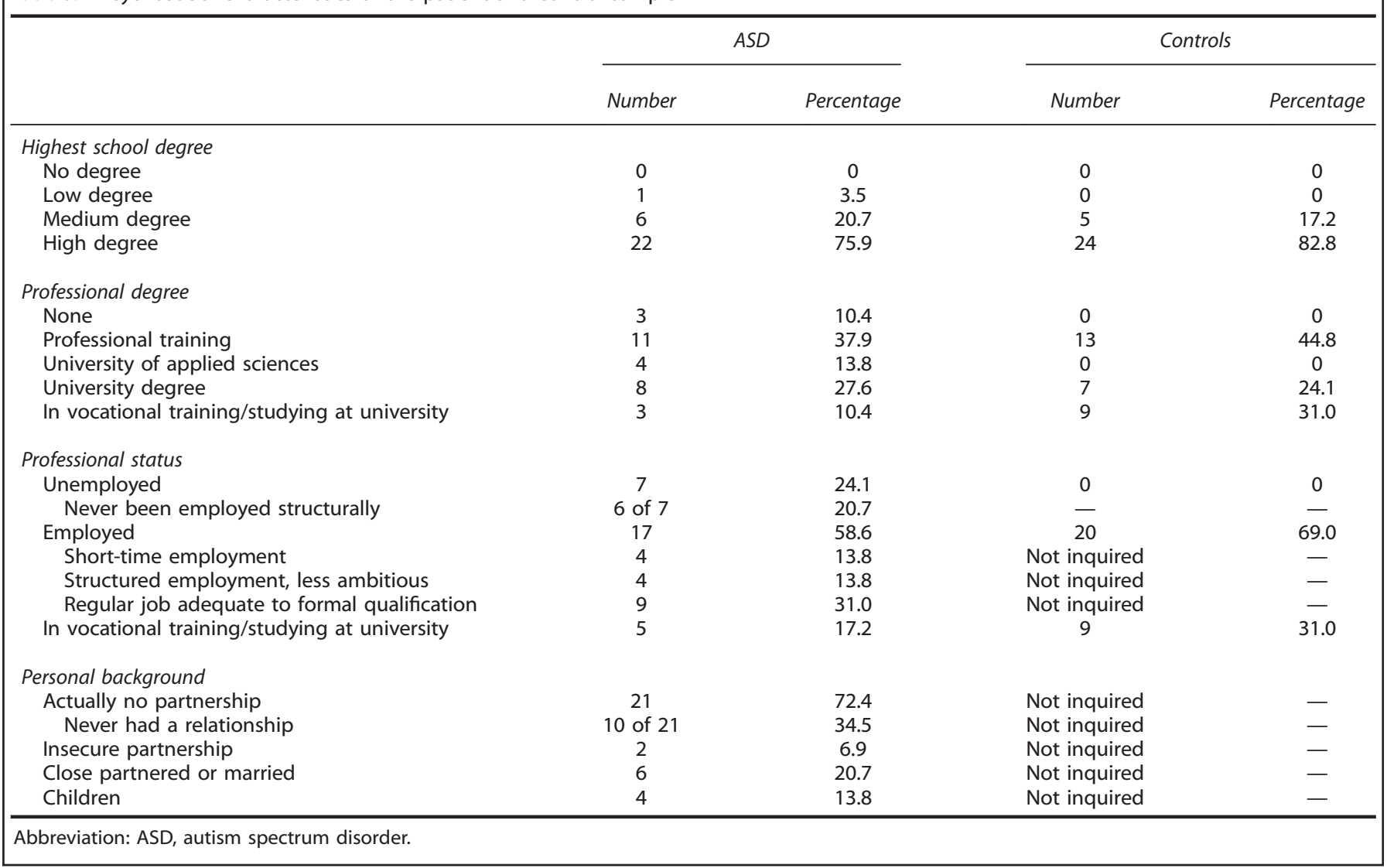

\begin{tabular}{|c|c|c|c|c|c|c|}
\hline & $A S D(I U)$ & Controls (IU) & Statistics MANCOVA & $A S D(I U)$ & Controls (IU) & Statistics MANCOVA \\
\hline & & Cerebellum & & & regenual ACC & \\
\hline \multirow[t]{2}{*}{$N$-acetyl-aspartate } & 8.7820 & 9.1737 & NS & 10.7955 & 11.7288 & $F=4.150$ \\
\hline & 0.90541 & 0.80986 & & 2.36460 & 0.70366 & $P=0.046$ \\
\hline \multirow[t]{2}{*}{ Creatine } & 9.1924 & 9.5265 & NS & 8.7101 & 9.1661 & NS \\
\hline & 1.24528 & 0.91922 & & 1.97411 & 1.00472 & \\
\hline \multirow[t]{2}{*}{ Choline } & 2.2917 & 2.3287 & NS & 2.3102 & 2.3463 & NS \\
\hline & 0.38749 & 0.26289 & & 0.53321 & 0.32521 & \\
\hline \multirow{2}{*}{ Myoinositol } & 5.1265 & 5.1008 & NS & 6.1680 & 6.2477 & NS \\
\hline & 0.77710 & 0.89321 & & 1.09450 & 0.94463 & \\
\hline \multirow[t]{2}{*}{ Glutamate } & 7.2863 & 7.5396 & NS & 10.0240 & 11.4823 & $F=9.870$ \\
\hline & 1.13160 & 0.94118 & & 2.10100 & 1.35408 & $P=0.003$ \\
\hline \multirow[t]{2}{*}{ Glutamine $^{a}$} & 4.0494 & 4.1463 & NS & 5.1819 & 5.5690 & NS \\
\hline & 0.46342 & 0.54071 & & 1.25356 & 1.43995 & \\
\hline Glutamate and & 10.6424 & 11.1369 & NS & 14.1885 & 16.6872 & $F=11.772$ \\
\hline glutamine & 1.54804 & 1.30998 & & 3.04758 & 2.46852 & $P=0.001$ \\
\hline
\end{tabular}

Abbreviations: ACC, anterior cingulate cortex; ASD, autism spectrum disorder; IU, institutional unit; MANCOVA, multiple analysis of covariance; NS, nonsignificant. ${ }^{a}$ Glutamine was calculated separately in a factorial analysis of variance (see text).

calculation did not result in a relevant change in the findings (MANCOVA: Wilks' lambda $=0.762, \mathrm{~F}=2.607, \mathrm{df}=6, \mathrm{dfE}=50$, $P=0.028$; between-subject effects: NAA MANCOVA: $F=4.090$, $P=0.048$, Glu MANCOVA: $F=9.694, P=0.003$ and Glx MANCOVA: $\mathrm{F}=12.249, P=0.001)$. Other than that, there were no significant spectroscopic differences in the ACC or in the cerebellum.

To assess the possible confounding relevance of the factor medication, we compared only fully unmedicated patients $(n=14)$ with the control group. Both groups were still matched for age ( $T=-0.758, \mathrm{df}=41, P=0.453), \mathrm{IQ}(T=0.025, \mathrm{df}=41, P=0.981)$ and gender $\left(X^{2}=0.006, \mathrm{df}=1, P=0.937\right)$. Although the finding of the decreased NAA signal failed to reach a level of significance in this constellation ( $T=-1.309, P=0.212)$, the Glx finding was still highly significant $(T=-2.889, P=0.006)$. In the factorial analysis of variance with medication as the cofactor, the dependent variable NAA just failed to reach a level of significance $(F=3.940, P=0.052)$, 


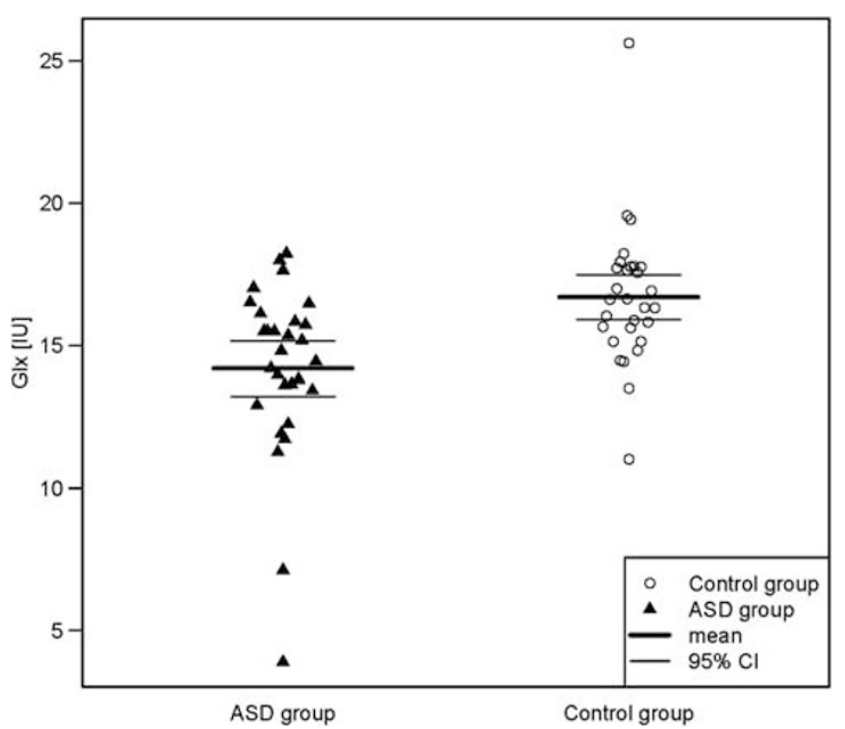

Figure 2. Illustration of decreased Glx signals in patients with ASD. ASD, autism spectrum disorder; Cl, confidence interval; Glx, glutamate and glutamine.

whereas the Glx signal again remained highly significant ( $\mathrm{F}=9.913, P=0.003)$.

\section{Analysis of dimensional associations}

Correlation analysis revealed a significant correlation between the ACC Glx signal and the AQ sum score $(r=-0.307, n=58, P=0.019)$, the AQ sub-score social skills $(r=-0.299, n=58, P=0.023)$ and the AQ sub-score sum communication ( $r=-0.393, n=58, P=0.002)$. The Glu signal correlated with the $\mathrm{AQ}$ sum score $(r=-0.283$, $n=58, P=0.031)$, the AQ sub-score communication $(r=-0.345$, $n=58, P=0.008)$ and the AQ sub-score imagination $(r=-0.291$, $n=58, P=0.027)$. When the patient and control groups were examined separately, no significant correlation between Glx and $\mathrm{AQ}$ or EQ scores was observed in either group. However, a significant correlation between the Glu signal and the EQ score remained in patients (EQ: $r=-0.378, n=29, P=0.043$ ). In the control group, the Glu signal was correlated with the AQ sub-score social skills $(r=0.369, n=29, P=0.049)$ and imagination $(r=$ $-0.396, n=29, P=0.033)$.

\section{DISCUSSION}

Thus far, this is the largest MRS study in adult patients with ASD. In addition, this is the first study in autism that examined only patients with above-average $\mathrm{IQ}$ in an attempt to generate a possibly homogenous study group. The main finding is decreased pregenual anterior cingulate NAA and Glx signals in patients with ASD. The decreased Glx signal but not the NAA signal was correlated with the social skills and communication measures. There was no evidence of altered neurochemistry in the cerebellum.

Possible implications of the main finding

To assess the possible relevance and implications of these findings, we first reviewed the literature on the ACC.

The role of the ACC in autism and social cognition

The ACC is a large limbic structure situated in the center of the brain and known to integrate information from various other brain areas. ${ }^{84}$ The ACC has been linked to functions such as attention control, empathy, performance and error monitoring, pain percep- tion, theory-of-mind faculties and behavioral adaptation to a changing environment. ${ }^{85-87}$ The rostral division consisting of Brodmann areas 12 and 32 (=pregenual ACC in this study) with predominantly affective functions can be distinguished from the caudal ACC (Brodmann area 32 and partly 24), which often is related to integrative cognitive aspects of information processing. ${ }^{84}$

The ACC has been shown to be of critical importance for joint attention mechanisms in chimpanzees. ${ }^{88}$ Deficits in joint attention are a critical early symptom in autism. Similar findings have been reported in human $\mathrm{fMRI}$ research. ${ }^{89}$ Related to this finding, Chang et al. analyzed the firing pattern of the ACC in social reward situations and found that it encoded complex reward allocations to other monkeys in group constellations. The authors concluded that the ACC is critical for computing shared experiences and social reward, ${ }^{90}$ which again relates well to our findings. Abnormal findings in ACC activity in ASD have also been reported in several fMRI studies. ${ }^{91-93}$ Furthermore, early as well as recent SPECT and PET studies in autism reported abnormalities in the ACC in terms of reduced blood flow, glucose metabolism and serotonin as well as dopamine receptor binding. ${ }^{94-97}$

Finally, postmortem research involving patients with ASD also pointed to decreased ACC cell density ${ }^{98}$ and abnormalities of the GABA receptors in the $A C C^{99}$ with the GABA system being the natural antagonist to Glu in keeping the excitatory-inhibitory homeostasis of the cerebral cortex. Taken together, these findings relate well to our observation of disrupted NAA and Glu metabolism in the ACC.

\section{Relationship to other findings}

As summarized in Table 1, up to now only 22 MRS studies have been conducted in autism. Quite a few of these studies are hampered by methodological limitations, and in early MRS research, it was not possible to reliably measure the Glu signal.

The first study that analyzed ACC neurochemistry in adults with AS was that by Oner et $a l^{57}$ In contrast to our finding of a decreased absolute NAA signal, they reported an increase in the $\mathrm{NAA} / \mathrm{Cho}$ ratio in the ACC. However, they measured only the metabolite/Cho ratios. In MRS research, metabolite ratios over Cre are often reported based on the assumption that the Cre concentration is stable, and thus represents a kind of constant reference measure. However, early MRS research raised doubts regarding whether this is really the case. ${ }^{100,101}$ Recent MRS metaanalyses clearly demonstrated differences in Cre as a function of age and the brain region. ${ }^{43,68,69}$ Therefore, metabolite/Cre ratios are very difficult to interpret. This is also true for metabolite ratios over Cho, as the variability of the Cho signal is even larger than that of the Cre signal. Therefore, Oner et al.'s data cannot answer the question if the observed changed ratio is due to a decreased NAA signal or alternatively to an increased Cho signal. Probably due to the methodological standard at that time, they were not able to report Glx signals at all.

In line with our finding, Bernardi et al. ${ }^{47}$ found decreased Glx signals in the right ACC in 14 adult patients with high-functioning ASD compared with 14 control subjects. In contrast, Bejjani et al. ${ }^{62}$ and Joshi et al. ${ }^{63}$ reported elevated Glu and Glx signals in the ACC. However, in contrast to our study, they investigated children and adolescents with a wide IQ range ${ }^{62}$ and a very small number of seven participants in the case of Joshi et al. ${ }^{63}$ study. Still, the question arises how these seemingly contradictory findings may be reconciled.

The hypothesis of excitatory/inhibitory imbalance in autism These findings could well be integrated within the theoretical framework of the hypothesis of excitatory/inhibitory imbalance in autism. As presented in the introduction, several authors have put forward the idea that such an imbalance between neuronal 
network excitation and inhibition might be a critical component in the pathogenesis of autism. ${ }^{16-18,102-105}$ This process, that is, the excitation/inhibition equilibrium (called neuronal homeostasis), can be defined as the ability of a neural system to return to a stable equilibrium following perturbation. ${ }^{104}$

From a theoretical point of view, it makes sense that the ACC is involved in the pathogenesis of ASD, as the ACC is important for mental faculties such as joint attention, attention to social reward, mental process and error monitoring, consciousness dissociation and affect regulation. ${ }^{106}$ Patients with ASD typically have problems in all these domains.

Our finding of a decreased ACC NAA concentration points to a relevant disturbance of the overall integrity of this region. Decreased NAA concentrations are seen, for example, in patients with neurodegenerative disorders. ${ }^{107}$ From this perspective, our finding is related to the report of decreased ACC cell density in postmortem research. ${ }^{98}$ It might also be related to reports of abnormalities in the histological organization of the isocortex in autism where the peripheral surroundings of minicolumns (composed primarily of inhibitory cells) have been reported to be altered, ${ }^{108}$ which in turn might cause an effective inhibitory deficit in that brain area. ${ }^{18}$ However, NAA decreases are also seen in transient disturbances of neuronal network integrity, such as ischemia or in other neuropsychiatric disorders, ${ }^{100,101,109,110}$ and may normalize following remission from a brain insult. ${ }^{109}$ From this perspective, our NAA finding is in line with reports of altered ACC blood flow and glucose metabolism in SPECT and PET studies. ${ }^{94-97}$ Although the decreased NAA signal represents only a marker of the overall compromised neuronal health of whatever cause in the measured region of interest, the compromised Glx signal might characterize the nature of the dysfunction more specifically.

When it comes to guarding the functional homeostasis of the cerebral cortex, the most important neurotransmitters for regulating neuronal network excitation and inhibition are Glu and GABA. In line with this hypothesis, almost all MRS studies investigating Glu and GABA found evidence of abnormal signals (see Table 1). However, although two studies in children and adolescents found increased Glx signals, we and Bernardi et al. ${ }^{47}$ found decreased Glx signals in adults.

In this context, the question arises as to what the Glx signal means in terms of pathophysiology. This issue has been addressed in many studies in epilepsy research. For example, Doelken et al. ${ }^{111}$ found increased Glx signals in a patient sample with highfrequency generalized tonic clonic seizures among other regions in the ACC. Peca et al. ${ }^{112}$ showed that experimentally induced epileptic activity led to an increase in the Glu and Gln signals as measured with MRS during the first 10 min of stimulation and then returned to baseline. Zahr et al. ${ }^{113}$ followed the MRS signal in Wistar rats with five kainic acid-induced seizures and showed that seizure activity causes a decrease in the Glu signal in the long run. Summarizing these findings, at least in animals, excitatory seizure activity results in an acute increase in the Glx signal and a decrease in this signal in the long run.

Against the background of these observations, the increased Glx signals reported in children and adolescents with ASD could be understood as an indicator of ACC overexcitation. Whereas the decreased ACC Glx signals we and others measured in adults might point to over-inhibition of this brain area. From this perspective, the MRS Glx signal might serve as a surrogate marker of the functional equilibrium of ACC networks, with increased signals pointing to pathological overactivation and decreased signals hinting at over-inhibition. Figure 3 illustrates the essence of this hypothesis of ACC imbalance in ASD.

This hypothesis has been put forward by several researchers in cognitive neuroscience. ${ }^{17,102-105}$ The idea that pathological inhibition in the context of neuronal network instability and disturbed functional homeostasis might represent a relevant pathomechanism at least in subgroups of different neuropsychiatric disorders has also been put forward by our group to explain the role of pathological EEG findings in different psychiatric disorders. ${ }^{23,106}$

One strength of this hypothesis is that it could not only integrate the findings summarized in MRS research but also explain the well-known link of ASD to epilepsy. ${ }^{6,114}$ In addition, as ASD has been linked to discrete neuroinflammatory processes and microglia activation, ${ }^{115}$ and neuroinflammation in turn has been associated with neuronal network excitation via glutamatergic mechanisms, ${ }^{116,117}$ Glu signal abnormalities in the ACC could be interpreted as a result of such pathomechanisms.

Further support of this assumption comes from data that show that proinflammatory cytokines correlate with 1H-MRS Glx signals in patients with liver failure. ${ }^{118}$ Finally, increased cerebral glutamatergic activity has been linked to discrete inflammatory

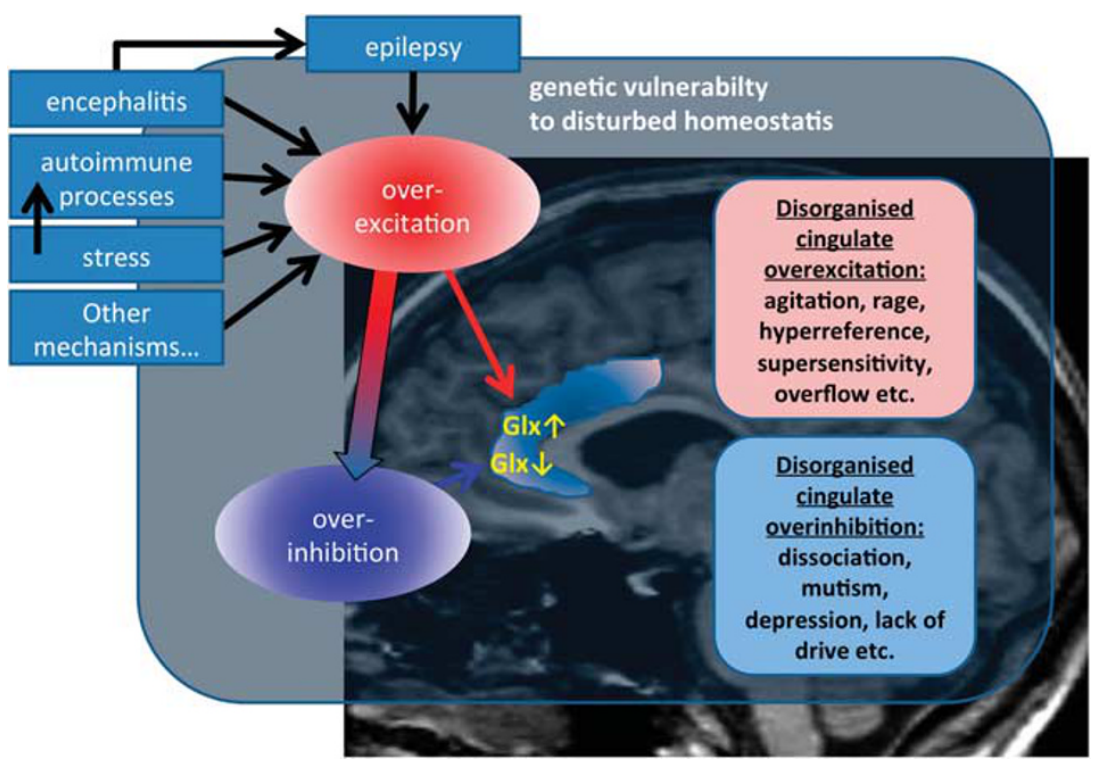

Figure 3. Illustration of the hypothesis of excitation/inhibition imbalance in autism. Glx, glutamate and glutamine. 
mechanisms in other neuropsychiatric disorders such as Alzheimer disease and epilepsy. ${ }^{114,119,120}$

In summary, our MRS findings and those of many other authors as well as many clinical phenomena could be integrated within the theoretical framework of the excitation/inhibition imbalance theory of autism. Optogenetic methods might be a promising tool for further validating this theory with the first encouraging results already published. ${ }^{102}$ In this context, MRS might turn out to be a critical translational research tool, as it can be used in animal and human research alike without any relevant side effects.

\section{Methodological issues}

Finally, methodological issues and limitations of this study must be considered. The present study was implemented following high methodological standards. The diagnosis of ASD was established in a multiprofessional diagnostic team in one leading German center for the diagnosis and treatment of ASDs in adults (Universitäres Zentrum Autismus Spektrum Freiburg, UZAS; http:// www.uniklinik-freiburg.de/psych/live/patientenversorgung/schwer punkte/schwerpunkt-asperger.html). In childhood and adolescence psychiatry and psychotherapy, the psychometric instruments $A D I-R^{79}$ and ADOS $^{80}$ are generally accepted as the gold standard for diagnosing ASD (http://guidance.nice.org.uk/CG128/ NICEGuidance/pdf/English). In adulthood, this type of gold standard has not yet been established. Empirical research proved that there is only moderate agreement between clinical consensus diagnoses and ADOS-based ratings for adults. ${ }^{121}$ In particular, the discrimination regarding schizophrenia can be a problem. ${ }^{122}$ In line with these observations, in a German sample that compared ADOS with expert-consent rating, there were relevant falsepositive and false-negative ADOS ratings. ${ }^{123}$ Given this background, we followed the diagnostic principles laid out for diagnostic process in adulthood by the NICE guidelines for adults closely (http://guidance.nice.org.uk/CG142/NICEGuidance/pdf/Eng lish) and used consent expert rating rather than ADOS and ADI-R as the decisive criteria for caseness.

Including patients only with above-average IQ may be regarded as a disadvantage or as an advantage. Obviously, the generalizability of our findings and the ecological validity are compromised by this approach, as only a subgroup of patients with ASD have above-average IQs. However, it might be regarded as an advantage that the issue of mental handicap and learning difficulties must not be considered an important confounding factor. Following the line of thought laid out in the introduction, the aim was to create a neurobiologically homogenous study sample.

The MRS data acquisition and analysis followed longestablished procedures at the Freiburg Brain Imaging Center (http://www.uniklinik-freiburg.de/fbi/live/index en.html) and was parallelized to a large government-funded study of patients with ADHD (BMBF 01GV0606). This fact also enabled us to match the control subjects from an available database of 90 controls. This allowed a one-to-one matching procedure in terms of gender and a very close individual match in terms of age and IQ.

We opted for single-voxel spectroscopy to avoid the problem of interpreting metabolite/Cre ratios. Several meta-analyses have pointed out that there is a relevant variance in Cre signals across age groups and brain areas, and therefore the commonly used procedure for calculating such ratios can lead to relevant problems when it comes to interpreting findings. ${ }^{43,68,69}$ All Glurelated MRS signals (Glu, Gln and Glx) measure the integrity of regional cerebral Glu metabolism. ${ }^{44}$ We present the figures for these signals but focused on the Glx signal because the spectral peaks of GIn and Glu overlap considerably, and therefore the collectively denoted Glx signal is more robust. ${ }^{45}$ In MRS research, neurometabolite signals, in particular Glx and NAA, generally are correlated. $^{124}$ Therefore, such correlations are not informative regarding the underlying pathomechanism of interest. The statistical procedure was straightforward, and individual raw data for all relevant findings have been presented as scatterplot figures. Therefore, all results are transparent to the reader.

In addition to the limited generalizability due to the high mean IQ of our sample, a larger sample size would have been desirable. However, to our knowledge, this is presently still the largest MRS study in adults and the first to focus on patients with aboveaverage IQ.

\section{Summary}

In summary, in this study, we found decreased NAA and Glx signals in the ACC of adult patients with ASD and above-average IQ. The Glx signal correlated with psychometric measures of autism, particularly with deficits in communication skills. The Glx finding is in line with the only other MRS study in adults, both reporting Glx reductions in the ACC. This is in contrast to two studies in children and adolescents that reported a Glx signal increase rather than a signal reduction in the ACC. Regarding the excitation/inhibition-imbalance hypothesis in autism, we interpret this signal as an expression of functional over-inhibition of this brain area in our patient sample. If replicated and validated in further research, the MRS-detectable Glx signals might be a valuable marker for assessing cerebral overexcitation or overinhibition in autism and other neuropsychiatric research. In this case, it could also be used as an objective surrogate marker of change and therapy response in psychotherapeutic and pharmacological interventions.

\section{CONFLICT OF INTEREST}

The authors declare no conflict of interest.

\section{ACKNOWLEDGMENTS}

Part of the study was supported by a grant from the federal Ministry of Education and Research to LTVE (BMBF 01GV0606).

\section{REFERENCES}

1 Centers for Disease Control and Prevention. Epidemiology, Autism Spectrum Disorder. http://www.cdc.gov/ncbddd/autism/data.html 4-7-2013.

2 Brugha TS, McManus S, Bankart J, Scott F, Purdon S, Smith J et al. Epidemiology of autism spectrum disorders in adults in the community in England. Arch Gen Psychiatry 2011; 68: 459-465.

3 Kim YS, Leventhal BL, Koh YJ, Fombonne E, Laska E, Lim EC et al. Prevalence of autism spectrum disorders in a total population sample. Am J Psychiatry 2011; 168: $904-912$.

4 Hofvander B, Delorme R, Chaste P, Nydén A, Wentz E, Ståhlberg O et al. Psychiatric and psychosocial problems in adults with normal-intelligence autism spectrum disorders. BMC Psychiatry 2009; 9: 35.

5 Tebartz van Elst L, Pick M, Biscaldi M, Fangmeier T, Riedel A. High-functioning autism spectrum disorder as a basic disorder in adult psychiatry and psychotherapy: psychopathological presentation, clinical relevance and therapeutic concepts. Eur Arch Psychiatry Clin Neurosci 2013; 263(Suppl 2): S189-S196.

6 Levy SE, Mandell DS, Schultz RT. Autism. Lancet 2009; 374: 1627-1638.

7 Moreno-De-Luca A, Myers SM, Challman TD, Moreno-De-Luca D, Evans DW, Ledbetter $\mathrm{DH}$. Developmental brain dysfunction: revival and expansion of old concepts based on new genetic evidence. Lancet Neurol 2013; 12: 406-414.

8 Cohen D, Pichard N, Tordjman S, Baumann C, Burglen L, Excoffier E et al. Specific genetic disorders and autism: clinical contribution towards their identification. J Autism Dev Disord 2005; 35: 103-116.

9 Lord C, Petkova E, Hus V, Gan W, Lu F, Martin DM et al. A multisite study of the clinical diagnosis of different autism spectrum disorders. Arch Gen Psychiatry 2012; 69: 306-313.

10 Sharma S, Woolfson LM, Hunter SC. Confusion and inconsistency in diagnosis of Asperger syndrome: a review of studies from 1981 to 2010. Autism 2012; 16: 465-486.

11 Persico AM, Napolioni V. Autism genetics. Behav Brain Res 2013; 251: 95-112. 
12 van Harssel JJ, Weckhuysen S, van Kempen MJ, Hardies K, Verbeek NE, de Kovel CG et al. Clinical and genetic aspects of PCDH19-related epilepsy syndromes and the possible role of $\mathrm{PCDH} 19$ mutations in males with autism spectrum disorders. Neurogenetics 2013; 14: 23-34.

13 Munoz-Yunta JA, Palau-Baduell M, Salvadó-Salvadó B, Valls-Santasusana A, Rosendo-Moreno N, Clofent-Torrentó et al. Autism, epilepsy and genetics. Rev Neurol 2008; 46(Suppl 1): S71-S77.

14 Chao HT, Chen H, Samaco RC, Xue M, Chahrour M, Yoo J et al. Dysfunction in GABA signalling mediates autism-like stereotypies and Rett syndrome phenotypes. Nature 2010; 468: 263-269.

15 Tarabeux J, Kebir O, Gauthier J, Hamdan FF, Xiong L, Piton A et al. Rare mutations in N-methyl-D-aspartate glutamate receptors in autism spectrum disorders and schizophrenia. Transl Psychiatry 2011; 1: e55.

16 Rubenstein JL. Three hypotheses for developmental defects that may underlie some forms of autism spectrum disorder. Curr Opin Neurol 2010; 23: 118-123.

17 Rubenstein JL, Merzenich MM. Model of autism: increased ratio of excitation/ inhibition in key neural systems. Genes Brain Behav 2003; 2: 255-267.

18 Casanova MF, Buxhoeveden D, Gomez J. Disruption in the inhibitory architecture of the cell minicolumn: implications for autism. Neuroscientist 2003; 9: 496-507.

19 Essa MM, Braidy N, Vijayan KR, Subash S, Guillemin GJ. Excitotoxicity in the pathogenesis of autism. Neurotox Res 2013; 23: 393-400.

20 Maski KP, Jeste SS, Spence SJ. Common neurological co-morbidities in autism spectrum disorders. Curr Opin Pediatr 2011; 23: 609-615.

21 Ballaban-Gil K, Tuchman R. Epilepsy and epileptiform EEG: association with autism and language disorders. Ment Retard Dev Disabil Res Rev 2000; 6 : 300-308.

22 Spence SJ, Schneider MT. The role of epilepsy and epileptiform EEGs in autism spectrum disorders. Pediatr Res 2009; 65: 599-606.

23 Tebartz van Elst L, Perlov E. Epilepsy \& Psyche. Psychische Störungen bei Epilepsie, Epileptische Phänomene in der Psychiatrie. Kohlhammer Verlag: Göttingen, Germany, 2013.

24 Jamain S, Betancur C, Quach H, Philippe A, Fellous M, Giros B et al. Linkage and association of the glutamate receptor 6 gene with autism. Mol Psychiatry 2002; 7 302-310.

25 Buttenschon HN, Lauritsen $M B$, El Daoud $A$, Hollegaard $M$, Jorgensen $M$, Tvedegaard $\mathrm{K}$ et al. A population-based association study of glutamate decarboxylase 1 as a candidate gene for autism. J Neural Transm 2009; 116: 381-388.

26 Butler PD, Zemon V, Schechter I, Saperstein AM, Hoptman MJ, Lim KO et al. Earlystage visual processing and cortical amplification deficits in schizophrenia. Arch Gen Psychiatry 2005; 62: 495-504.

27 Yang Y, Pan C. Role of metabotropic glutamate receptor 7 in autism spectrum disorders: a pilot study. Life Sci 2013; 92: 149-153.

28 Won H, Lee HR, Gee HY, Mah W, Kim Jl, Lee J et al. Autistic-like social behaviour in Shank2-mutant mice improved by restoring NMDA receptor function. Nature 2012; 486: 261-265.

29 Kelleher RJ III, Geigenmüller U, Hovhannisyan H, Trautman E, Pinard R, Rathmell $B$ et al. High-throughput sequencing of mGluR signaling pathway genes reveals enrichment of rare variants in autism. PLoS One 2012; 7: e35003.

30 Mehta MV, Gandal MJ, Siegel SJ. mGluR5-antagonist mediated reversal of elevated stereotyped, repetitive behaviors in the VPA model of autism. PLoS One 2011; 6: e26077.

31 Jacob S, Brune CW, Badner JA, Ernstrom K, Courchesne E, Lord C et al. Familybased association testing of glutamate transporter genes in autism. Psychiatr Genet 2011; 21: 212-213.

32 Turunen JA, Rehnström K, Kilpinen H, Kuokkanen M, Kempas E, Ylisaukko-Oja T. Mitochondrial aspartate/glutamate carrier SLC25A12 gene is associated with autism. Autism Res 2008; 1: 189-192.

33 Autism Genome Project Consortium, Szatmari P, Paterson AD, Zwaigenbaum L, Roberts W, Brian J et al. Mapping autism risk loci using genetic linkage and chromosomal rearrangements. Nat Genet 2007; 39: 319-328.

34 Ramoz N, Reichert JG, Smith CJ, Silverman JM, Bespalova IN, Davis KL et al. Linkage and association of the mitochondrial aspartate/glutamate carrier SLC25A12 gene with autism. Am J Psychiatry 2004; 161: 662-669.

35 Bristot Silvestrin R, Bambini-Junior V, Galland F, Daniele Bobermim L, QuincozesSantos A, Torres Abib $R$ et al. Animal model of autism induced by prenatal exposure to valproate: altered glutamate metabolism in the hippocampus. Brain Res 2013; 1495: 52-60.

36 Markram K, Markram $\mathrm{H}$. The intense world theory-a unifying theory of the neurobiology of autism. Front Hum Neurosci 2010; 4: 224

37 Purcell $A E$, Jeon $\mathrm{OH}$, Zimmerman AW, Blue ME, Pevsner J. Postmortem brain abnormalities of the glutamate neurotransmitter system in autism. Neurology 2001; 57: 1618-1628.

38 Shimmura C, Suda S, Tsuchiya KJ, Hashimoto K, Ohno K, Matsuzaki H et al. Alteration of plasma glutamate and glutamine levels in children with highfunctioning autism. PLoS One 2011; 6: e25340.
39 Shimmura C, Suzuki K, Iwata Y, Tsuchiya KJ, Ohno K, Matsuzaki H et al. Enzymes in the glutamate-glutamine cycle in the anterior cingulate cortex in postmortem brain of subjects with autism. Mol Autism 2013; 4: 6 .

40 Carlsson ML. Hypothesis: is infantile autism a hypoglutamatergic disorder? Relevance of glutamate-serotonin interactions for pharmacotherapy. J Neural Transm 1998; 105: 525-535.

41 Fatemi SH. The hyperglutamatergic hypothesis of autism. Prog Neuropsychopharmacol Biol Psychiatry 2008; 32: 911.

42 Fatemi SH, Halt AR, Stary JM, Kanodia R, Schulz SC, Realmuto GR. Glutamic acid decarboxylase 65 and $67 \mathrm{kDa}$ proteins are reduced in autistic parietal and cerebellar cortices. Biol Psychiatry 2002; 52: 805-810.

43 Baruth JM, Wall CA, Patterson MC, Port JD. Proton magnetic resonance spectroscopy as a probe into the pathophysiology of autism spectrum disorders (ASD): a review. Autism Res 2013; 6: 119-133.

44 Tebartz van Elst LT, Valerius G, Büchert M, Thiel T, Rüsch N, Bubl E et al. Increased prefrontal and hippocampal glutamate concentration in schizophrenia: evidence from a magnetic resonance spectroscopy study. Biol Psychiatry 2005; 58: 724-730.

45 Bartha R, Williamson PC, Drost DJ, Malla A, Carr TJ, Cortese L et al. Measurement of glutamate and glutamine in the medial prefrontal cortex of never-treated schizophrenic patients and healthy controls by proton magnetic resonance spectroscopy. Arch Gen Psychiatry 1997; 54: 959-965.

46 Corrigan NM, Shaw DW, Richards TL, Estes AM, Friedman SD, Petropoulos $\mathrm{H}$ et al. Proton magnetic resonance spectroscopy and MRI reveal no evidence for brain mitochondrial dysfunction in children with autism spectrum disorder. $J$ Autism Dev Disord 2012; 42: 105-115.

47 Bernardi S, Anagnostou E, Shen J, Kolevzon A, Buxbaum JD, Hollander E et al. In vivo $1 \mathrm{H}$-magnetic resonance spectroscopy study of the attentional networks in autism. Brain Res 2011; 1380: 198-205.

48 Fujii E, Mori K, Miyazaki M, Hashimoto T, Harada M, Kagami S. Function of the frontal lobe in autistic individuals: a proton magnetic resonance spectroscopic study. J Med Invest 2010; 57: 35-44.

49 Suzuki K, Nishimura K, Sugihara G, Nakamura K, Tsuchiya KJ, Matsumoto K et al. Metabolite alterations in the hippocampus of high-functioning adult subjects with autism. Int J Neuropsychopharmacol 2010; 13: 529-534.

50 Montag C, Schubert F, Heinz A, Gallinat J. Prefrontal cortex glutamate correlates with mental perspective-taking. PLoS One 2008; 3: e3890.

51 Hardan AY, Minshew NJ, Melhem NM, Srihari S, Jo B, Bansal R et al. An MRI and proton spectroscopy study of the thalamus in children with autism. Psychiatry Res 2008; 163: 97-105

52 Endo T, Shioiri T, Kitamura H, Kimura T, Endo S, Masuzawa $\mathrm{N}$ et al. Altered chemical metabolites in the amygdala-hippocampus region contribute to autistic symptoms of autism spectrum disorders. Biol Psychiatry 2007; 62: 1030-1037.

53 Fayed N, Modrego PJ. Comparative study of cerebral white matter in autism and attention-deficit/hyperactivity disorder by means of magnetic resonance spectroscopy. Acad Radiol 2005; 12: 566-569.

54 Murphy DG, Critchley HD, Schmitz N, McAlonan G, Van Amelsvoort T, Robertson $\mathrm{D}$ et al. Asperger syndrome: a proton magnetic resonance spectroscopy study of brain. Arch Gen Psychiatry 2002; 59: 885-891.

55 Page LA, Daly E, Schmitz N, Simmons A, Toal F, Deeley Q et al. In vivo $1 \mathrm{H}$-magnetic resonance spectroscopy study of amygdala-hippocampal and parietal regions in autism. Am J Psychiatry 2006; 163: 2189-2192.

56 Friedman SD, Shaw DW, Artru AA, Dawson G, Petropoulos H, Dager SR. Gray and white matter brain chemistry in young children with autism. Arch Gen Psychiatry 2006; 63: 786-794

57 Oner O, Devrimci-Ozguven H, Oktem F, Yagmurlu B, Baskak B, Munir KM. Proton MR spectroscopy: higher right anterior cingulate $\mathrm{N}$-acetylaspartate/choline ratio in Asperger syndrome compared with healthy controls. AJNR Am J Neuroradiol 2007; 28: 1494-1498.

58 Harada M, Taki MM, Nose A, Kubo H, Mori K, Nishitani $\mathrm{H}$ et al. Non-invasive evaluation of the GABAergic/glutamatergic system in autistic patients observed by MEGA-editing proton MR spectroscopy using a clinical 3 tesla instrument. J Autism Dev Disord 2011; 41: 447-454.

59 Vasconcelos MM, Brito AR, Domingues RC, da Cruz LC Jr, Gasparetto EL, Werner J $\mathrm{Jr}$ et al. Proton magnetic resonance spectroscopy in school-aged autistic children. J Neuroimaging 2008; 18: 288-295.

60 Zeegers M, van der GJ, van Daalen E, Buitelaar J, Van Engeland H. Proton magnetic resonance spectroscopy in developmentally delayed young boys with or without autism. J Neural Transm 2007; 114: 289-295.

61 Kubas B, Kułak W, Sobaniec W, Tarasow E, Lebkowska U, Walecki J. Metabolite alterations in autistic children: a 1H MR spectroscopy study. Adv Med Sci 2012; 57: 152-156.

62 Bejjani A, O'Neill J, Kim JA, Frew AJ, Yee VW, Ly R et al. Elevated glutamatergic compounds in pregenual anterior cingulate in pediatric autism 
spectrum disorder demonstrated by $1 \mathrm{H}$ MRS and 1H MRSI. PLoS One 2012; 7: e38786

63 Joshi G, Biederman J, Wozniak J, Goldin RL, Crowley D, Furtak S et al. Magnetic resonance spectroscopy study of the glutamatergic system in adolescent males with high-functioning autistic disorder: a pilot study at 4T. Eur Arch Psychiatry Clin Neurosci 2012; 263: 379-384.

64 Aoki Y, Abe O, Yahata N, Kuwabara H, Natsubori T, Iwashiro N et al. Absence of age-related prefrontal NAA change in adults with autism spectrum disorders. Transl Psychiatry 2012; 2: e178.

65 Mori K, Toda Y, Ito H, Mori T, Goji A, Fujii E et al. A proton magnetic resonance spectroscopic study in autism spectrum disorders: amygdala and orbitofrontal cortex. Brain Dev 2013; 35: 139-145.

66 Brown MS, Singel D, Hepburn S, Rojas DC. Increased glutamate concentration in the auditory cortex of persons with autism and first-degree relatives: a (1)H-MRS study. Autism Res 2013; 6: 1-10.

67 Rojas DC, Singel D, Steinmetz S, Hepburn S, Brown MS. Decreased left perisylvian GABA concentration in children with autism and unaffected siblings. Neuroimage 2013; 86: 28-34.

68 Aoki Y, Kasai K, Yamasue H. Age-related change in brain metabolite abnormalities in autism: a meta-analysis of proton magnetic resonance spectroscopy studies. Transl Psychiatry 2012; 2: e69.

69 Ipser JC, Syal S, Bentley J, Adnams CM, Steyn B, Stein DJ. 1H-MRS in autism spectrum disorders: a systematic meta-analysis. Metab Brain Dis 2012; 27: 275-287.

70 Philipsen A, Graf E, Jans T, Matthies S, Borel P, Colla M et al. A randomized controlled multicenter trial on the multimodal treatment of adult attentiondeficit hyperactivity disorder: enrollment and characteristics of the study sample. Atten Defic Hyperact Disord 2014; 6: 35-47.

71 Baron-Cohen S, Wheelwright S, Skinner R, Martin J, Clubley E. The autismspectrum quotient $(\mathrm{AQ})$ : evidence from Asperger syndrome/high-functioning autism, males and females, scientists and mathematicians. J Autism Dev Disord 2001; 31: 5-17.

72 Baron-Cohen S, Wheelwright S. The empathy quotient: an investigation of adults with Asperger syndrome or high functioning autism, and normal sex differences. J Autism Dev Disord 2004; 34: 163-175.

73 Garnett M, Attwood T. The diagnosis. In: Attwood T (ed). Asperger's Syndrome: a Guide for Parents and Professionals. Jessica Kingsley: London, UK, 1998.

74 Constantiono JN, Gruber CP. Social Responsiveness Scale. Western Psychological Services: Los Angeles, CA, USA, 2005.

75 Vorst HCM, Bermond B. Validity and reliability of the Bermond-Vorst Alexithymia Questionnaire. Pers Indiv Differ 2001; 30: 413-421.

76 Baron-Cohen S, Wheelwright S, Robinson J, Woodbury-Smith M. The Adult Asperger Assessment (AAA): a diagnostic method. J Autism Dev Disord 2005; 35: 807-819.

77 Retz-Junginger P, Retz W, Blocher D, Weijers HG, Trott GE, Wender PH et al. Wender Utah Rating Scale (WURS-K). Nervenarzt 2002; 73: 830-838.

78 Hautzinger M. The Beck Depression Inventory (BDI) in clinical use. [German] Nervenarzt 1997; 62: 28-34.

79 Lord C, Rutter M, Le Couteur A. Autism Diagnostic Interview-Revised: a revised version of a diagnostic interview for caregivers of individuals with possible pervasive developmental disorders. J Autism Dev Disord 1994; 24: 659-685.

80 Lord C, Risi S, Lambrecht L, Cook EH Jr, Leventhal BL, DiLavore PC et al. The autism diagnostic observation schedule-generic: a standard measure of social and communication deficits associated with the spectrum of autism. J Autism Dev Disord 2000; 30: 205-223.

81 Lehrl S. Mehrfachwahl-Wortschatz-Intelligenztest (MWT-B). Spitta Verlag: Balingen, Germany, 1999.

82 Provencher SW. LC Model and LCMgui. User's Manual http://s-provencher.com/ pub/LCModel/manual/manual.pdf 2005.

83 Bolliger CS, Boesch C, Kreis R. On the use of Cramér-Rao minimum variance bounds for the design of magnetic resonance spectroscopy experiments. Neuroimage 2013; 83: 1031-1040.

84 Bush G, Luu P, Posner MI. Cognitive and emotional influences in anterior cingulate cortex. Trends Cogn Sci 2000; 4: 215-222.

85 MacDonald AW III, Cohen JD, Stenger VA, Carter CS. Dissociating the role of the dorsolateral prefrontal and anterior cingulate cortex in cognitive control. Science 2000; 288: 1835-1838.

86 Decety J. The neurodevelopment of empathy in humans. Dev Neurosci 2010; 32 257-267.

87 Vollm BA, Taylor AN, Richardson P, Corcoran R, Stirling J, McKie S et al. Neuronal correlates of theory of mind and empathy: a functional magnetic resonance imaging study in a nonverbal task. Neuroimage 2006; 29: 90-98.

88 Hopkins WD, Taglialatela JP. Initiation of joint attention is associated with morphometric variation in the anterior cingulate cortex of chimpanzees (pan troglodytes). Am J Primatol 2013; 75: 441-449.
89 Williams JH, Waiter GD, Gilchrist A, Perrett DI, Murray AD, Whiten A. Neural mechanisms of imitation and 'mirror neuron' functioning in autistic spectrum disorder. Neuropsychologia 2006; 44: 610-621.

90 Chang SW, Gariepy JF, Platt ML. Neuronal reference frames for social decisions in primate frontal cortex. Nat Neurosci 2013; 16: 243-250.

91 Minshew NJ, Keller TA. The nature of brain dysfunction in autism: functional brain imaging studies. Curr Opin Neurol 2010; 23: 124-130.

92 Thakkar KN, Polli FE, Joseph RM, Tuch DS, Hadjikhani N, Barton JJ et al. Response monitoring, repetitive behaviour and anterior cingulate abnormalities in autism spectrum disorders (ASD). Brain 2008; 131: 2464-2478.

93 Marsh LE, Hamilton AF. Dissociation of mirroring and mentalising systems in autism. Neuroimage 2011; 56: 1511-1519.

94 Baron-Cohen S, Ring H, Moriarty J, Schmitz B, Costa D, Ell P. Recognition of mental state terms. Clinical findings in children with autism and a functional neuroimaging study of normal adults. Br J Psychiatry 1994; 165: 640-649.

95 Haznedar MM, Buchsbaum MS, Metzger M, Solimando A, Spiegel-Cohen J, Hollander E.. Anterior cingulate gyrus volume and glucose metabolism in autistic disorder. Am J Psychiatry 1997; 154: 1047-1050.

96 Haznedar MM, Buchsbaum MS, Wei TC, Hof PR, Cartwright C, Bienstock CA et al. Limbic circuitry in patients with autism spectrum disorders studied with positron emission tomography and magnetic resonance imaging. Am J Psychiatry 2000; 157: 1994-2001.

97 Nakamura K, Sekine Y, Ouchi Y, Tsujii M, Yoshikawa E, Futatsubashi M et al. Brain serotonin and dopamine transporter bindings in adults with highfunctioning autism. Arch Gen Psychiatry 2010; 67: 59-68.

98 Simms ML, Kemper TL, Timbie CM, Bauman ML, Blatt GJ. The anterior cingulate cortex in autism: heterogeneity of qualitative and quantitative cytoarchitectonic features suggests possible subgroups. Acta Neuropathol 2009; 118: 673-684.

99 Oblak AL, Gibbs TT, Blatt GJ. Decreased GABA(B) receptors in the cingulate cortex and fusiform gyrus in autism. J Neurochem 2010; 114: 1414-1423.

100 Tebartz van Elst LT, Thiel T, Hesslinger B, Lieb K, Bohus M, Hennig J et al. Subtle prefrontal neuropathology in a pilot magnetic resonance spectroscopy study in patients with borderline personality disorder. J Neuropsychiatry Clin Neurosci 2001; 13: 511-514.

101 Tebartz van Elst L, Ludaescher $\mathrm{P}$, Thiel T, Büchert M, Hesslinger B, Bohus $M$ et al. Evidence of disturbed amygdalar energy metabolism in patients with borderline personality disorder. Neurosci Lett 2007; 417: 36-41.

102 Yizhar O, Fenno LE, Prigge M, Schneider F, Davidson TJ, O'Shea DJ et al. Neocortical excitation/inhibition balance in information processing and social dysfunction. Nature 2011; 477: 171-178.

103 Gogolla N, Leblanc JJ, Quast KB, Südhof TC, Fagiolini M, Hensch TK. Common circuit defect of excitatory-inhibitory balance in mouse models of autism. J Neurodev Disord 2009; 1: 172-181.

104 Ramocki MB, Zoghbi HY. Failure of neuronal homeostasis results in common neuropsychiatric phenotypes. Nature 2008; 455: 912-918.

105 Tabuchi K, Blundell J, Etherton MR, Hammer RE, Liu X, Powell CM et al. A neuroligin-3 mutation implicated in autism increases inhibitory synaptic transmission in mice. Science 2007; 318: 71-76.

106 Tebartz van Elst L, Krishnamoorthy ES, Schulze-Bonhage A, Altenmüller DM Richter H, Ebert D et al. Local area network inhibition: a model of a potentially important paraepileptic pathomechanism in neuropsychiatric disorders. Epilepsy Behav 2011; 22: 231-239.

107 Soher BJ, Doraiswamy PM, Charles HC. A review of 1H MR spectroscopy findings in Alzheimer's disease. Neuroimaging Clin N Am 2005; 15: 847-852, xi.

108 Casanova MF, El-Baz A, Vanbogaert E, Narahari P, Switala A. A topographic study of minicolumnar core width by lamina comparison between autistic subjects and controls: possible minicolumnar disruption due to an anatomical element in-common to multiple laminae. Brain Pathol 2010; 20: 451-458.

109 Dautry C, Vaufrey F, Brouillet E, Bizat N, Henry PG, Condé F et al. Early N-acetylaspartate depletion is a marker of neuronal dysfunction in rats and primates chronically treated with the mitochondrial toxin 3-nitropropionic acid. J Cereb Blood Flow Metab 2000; 20: 789-799.

110 Perlov E, Philipsen A, Matthies S, Drieling T, Maier S, Bubl E et al. Spectroscopic findings in attention-deficit/hyperactivity disorder: review and meta-analysis. World J Biol Psychiatry 2009; 10: 355-365.

111 Doelken MT, Mennecke A, Stadlbauer A, Kecskeméti L, Kasper BS, Struffert T et al. Multi-voxel magnetic resonance spectroscopy at $3 \mathrm{~T}$ in patients with idiopathic generalised epilepsy. Seizure 2010; 19: 485-492.

112 Peca S, Carnì M, Di Bonaventura C, Aprile T, Hagberg GE, Giallonardo AT et al. Metabolic correlatives of brain activity in a FOS epilepsy patient. NMR Biomed 2010; 23: 170-178.

113 Zahr NM, Crawford EL, Hsu O, Vinco S, Mayer D, Rohlfing T et al. In vivo glutamate decline associated with kainic acid-induced status epilepticus. Brain Res 2009; 1300: 65-78. 
114 Vezzani A, Granata T. Brain inflammation in epilepsy: experimental and clinical evidence. Epilepsia 2005; 46: 1724-1743.

115 Tetreault NA, Hakeem AY, Jiang S, Williams BA, Allman E, Wold BJ et al. Microglia in the cerebral cortex in autism. J Autism Dev Disord 2012; 42: 2569-2584.

116 Degos V, Peineau S, Nijboer C, Kaindl AM, Sigaut S, Favrais G et al. G proteincoupled receptor kinase 2 and group I metabotropic glutamate receptors mediate inflammation-induced sensitization to excitotoxic neurodegeneration. Ann Neurol 2013; 73: 667-678.

117 Takaki J, Fujimori K, Miura M, Suzuki T, Sekino Y, Sato K. L-glutamate released from activated microglia downregulates astrocytic L-glutamate transporter expression in neuroinflammation: the 'collusion' hypothesis for increased extracellular L-glutamate concentration in neuroinflammation. J Neuroinflammation 2012; 9: 275.

118 Gupta RK, Yadav SK, Rangan M, Rathore RK, Thomas MA, Prasad KN et al. Serum proinflammatory cytokines correlate with diffusion tensor imaging derived metrics and 1H-MR spectroscopy in patients with acute liver failure. Metab Brain Dis 2010; 25: 355-361.

119 Ringheim GE, Szczepanik AM. Brain inflammation, cholesterol, and glutamate as interconnected participants in the pathology of Alzheimer's disease. Curr Pharm Des 2006; 12: 719-738.

120 McNally L, Bhagwagar Z, Hannestad J. Inflammation, glutamate, and glia in depression: a literature review. CNS Spectr 2008; 13: 501-510.
121 Brugha TS, McManus S, Smith J, Scott FJ, Meltzer H, Purdon S et al. Validating two survey methods for identifying cases of autism spectrum disorder among adults in the community. Psychol Med 2012; 42: 647-656.

122 Bastiaansen JA, Meffert H, Hein S, Huizinga P, Ketelaars C, Pijnenborg et al. Diagnosing autism spectrum disorders in adults: the use of Autism Diagnostic Observation Schedule (ADOS) module 4. J Autism Dev Disord 2011; 41: 1256-1266.

123 Becker J, Kamp-Becker I. Die Diagnose des Asperger Syndroms bei erwachsenen Menschen, klinische Erfahrungen unter besonderer Berücksichtigung der Diagnostischen Beobachtungssklala für Autistische Störungen (ADOS). 5. Wissenschaftliche Tagung Autismus Spektrum: 29. 2012. Wissenschaftliche Gesellschaft Autismus Spektrum. Tagungsband.

124 Provencher SW. Automatic quantitation of localized in vivo $1 \mathrm{H}$ spectra with LCModel. NMR Biomed 2001; 14: 260-264.

(i) $\Theta$ This work is licensed under a Creative Commons AttributionNonCommercial-NoDerivs 3.0 Unported License. The images or other third party material in this article are included in the article's Creative Commons license, unless indicated otherwise in the credit line; if the material is not included under the Creative Commons license, users will need to obtain permission from the license holder to reproduce the material. To view a copy of this license, visit http://creativecommons.org/licenses/by-nc-nd/3.0/ 